\title{
Seasonal Influenza Vaccine: Uptake, Attitude, and Knowledge Among Patients Receiving Immunoglobulin Replacement Therapy
}

\author{
Fionnuala $\operatorname{Cox}^{1}$ (D) $\cdot$ Catherine King $^{1} \cdot$ Anne Sloan $^{1} \cdot$ David J. Edgar ${ }^{1,2} \cdot$ Niall Conlon ${ }^{1,2}$
}

Received: 17 August 2020 / Accepted: 13 November 2020 / Published online: 5 January 2021

(C) The Author(s) 2021

\begin{abstract}
Influenza is a potential cause of severe disease in the immunocompromised. Patients with hypogammaglobulinemia, in spite of adequate replacement therapy, are at risk of significant morbidity and adverse outcomes. A seasonal vaccine is the primary prophylactic countermeasure to limit disease. The aim of this study was to evaluate the attitude, knowledge, and influenza vaccine uptake among Irish patients receiving immunoglobulin replacement therapy (IgRT), as well as uptake in co-habitants. Fifty-seven percent of patients receiving IgRT at a regional immunology referral center completed a questionnaire evaluation. Seventy-six percent of IgRT patients received the influenza vaccine for the 2019 season. Ninety-eight percent recognized that influenza could be prevented with vaccination, and $81 \%$ deemed it a safe treatment. Ninety-three percent correctly identified that having a chronic medical condition, independent of age, was an indication for vaccination. Despite excellent compliance and knowledge, many were not aware that vaccination was recommended for co-habitants, and only $24 \%$ had full vaccine coverage at home. Those who received advice regarding vaccination of household members had higher rates of uptake at home. This study demonstrates awareness and adherence to seasonal influenza vaccine recommendations among patients receiving IgRT. Over three quarters felt adequately informed, the majority stating physicians as their information source. We identified an easily modifiable knowledge gap regarding vaccination of household members. This data reveals a need to emphasize the importance of vaccination for close contacts of at-risk patients, to maintain optimal immunity and health outcome.
\end{abstract}

Keywords Influenza vaccine $\cdot$ Immunoglobulin replacement therapy $\cdot$ IVIg $\cdot$ SCIg $\cdot$ Hypogammaglobulinemia

\section{Introduction}

Seasonal influenza is a transmissible acute respiratory illness that causes a mild infection in the majority of people. It is a public health concern as high-risk populations have an increased likelihood of severe disease [1,2]. There are year-toyear minor antigenic drift and periodic major antigenic shift; thus, annual vaccination is required and has been shown to effectively reduce morbidity and mortality $[3,4]$.

Infection-related complications are more prevalent in immunocompromised individuals, those over 65 years of age, people with chronic health conditions, and pregnant women [5-8]. The

Fionnuala Cox and Niall Conlon are first/senior authors.

Fionnuala Cox coxff@tcd.ie

1 Department of Immunology, St. James's Hospital, Dublin 8, Ireland

2 Department of Immunology, School of Medicine, Trinity College Dublin, Dublin, Ireland
World Health Organization (WHO) estimates over 40,000 people in the European Union die prematurely each year from influenza-related complications, and this figure can be reduced if at least $75 \%$ vaccine coverage is attained in risk groups [9, 10]. Disease surveillance is undertaken in most developed countries; however, many nations, including Ireland, have no central registry for vaccine monitoring $[11,12]$.

Patients with hypogammaglobulinemia are particularly susceptible to disease affecting the respiratory tract [13]. Regular immunoglobulin replacement therapy (IgRT), intravenous or subcutaneous, is the mainstay of management for these patients. Pooled immunoglobulin provides protective titers to most common vaccine agents (mumps, rubella, varicella); however, protection against influenza is ineffective due to antigenic drift $[14,15]$. Patients can glean some protective benefit from vaccination, despite impaired ability to develop antibodies; thus, annual vaccination is recommended $[16,17]$. In this setting, vaccination of close contacts is vital to limit transmission. Irish and most international guidelines specifically advise vaccination for healthcare workers, carers, and co-habitants of at-risk populations [18-20]. 
International data demonstrated that failure of patients to identify as "at-risk" as well as perceived cost of vaccination are negative determinants for compliance [21, 22]. Of concern, Irish population-based figures demonstrated a disappointing $28 \%$ uptake in those $<65$ years with a chronic medical condition, while a $60 \%$ uptake in individuals $\geq 65$ years still falls short of WHO target coverage [21]. Similar low rates of vaccine uptake are reflected in population-based studies of many developed nations [23, 24].

Global data consistently report suboptimal vaccine uptake in adults with chronic medical conditions; however, there is scant information available on vaccine compliance in those with immunodeficiency disorders [25]. Those with hypogammaglobulinemia are specifically vulnerable to infectious complications leading to hospital admission and adverse health outcomes [17]. Understanding influenza vaccine coverage and attitudes toward vaccination in this group is of particular importance to tailor education and identify specific barriers.

The objectives of this study were to measure seasonal influenza vaccine uptake among patients receiving regular IgRT in our center and to explore knowledge and attitudes toward the influenza vaccine in this population.

\section{Methods}

Information was gathered from November 2019 to March 2020, among adults receiving regular IgRT under the care of the Immunology department in a large Irish tertiary referral hospital. A previously validated questionnaire was used with minor modifications ([22] Appendix). The questionnaire covered four domains: demographics, vaccination and health status, knowledge and education, and co-habitant vaccination. All home-based and hospital day ward-based patients receiving IgRT were invited to take part. Vaccination was not provided by the Immunology department; thus, the data reflects patients receiving vaccination in the community.

Responses were anonymized. The study design and questionnaire were approved by the local Research Ethics Committee (Appendix). Descriptive statistics and chisquared analysis were applied where relevant and statistical significance set at $p<0.05$.

\section{Results}

The response rate to the questionnaire was $57 \%(55 / 97)$. Socio-demographic characteristics are detailed in Table 1. The mean age of participants was 51.5 years (22-80 years), and there was a slight male predominance (56\%; Table 1). Education status was high among participants; $62 \%$ had a tertiary level qualification, and $27 \%$ had completed secondary level studies. A sizable portion, 67\%, had access to a medical or general practitioner (GP) visit card, thus are eligible for free public health services in Ireland, compared with approximately $30 \%$ of the general population ([26]; Table 1). Granting of a medical/GP card is primarily based on income grounds, or if the burden of healthcare costs would result in hardship.
Table 1 Demographics of study participants. Mean age was 51.5 years, and $56 \%$ were male. Educational attainment was high, but this did not significantly impact on vaccine status. Access to a medical/GP card was associated with increased vaccine uptake, which was independent of solely having access to free vaccination. Chi-squared results are represented by $p$ values, ${ }^{*} p<0.05$

\begin{tabular}{|c|c|c|c|c|}
\hline & \multirow[t]{2}{*}{ Number $(\%)$} & \multicolumn{2}{|c|}{ Vaccination } & \multirow[t]{2}{*}{ Chi-squared } \\
\hline & & Yes $(\%)$ & No $(\%)$ & \\
\hline \multicolumn{5}{|l|}{ Age } \\
\hline $18-49$ & $28(51 \%)$ & $21(75 \%)$ & $7(25 \%)$ & \multirow[t]{3}{*}{0.58} \\
\hline $50-64$ & $13(24 \%)$ & $9(69 \%)$ & $4(31 \%)$ & \\
\hline$>65$ & $14(25 \%)$ & $12(86 \%)$ & $2(14 \%)$ & \\
\hline \multicolumn{5}{|l|}{ Gender } \\
\hline Male & $31(56 \%)$ & $20(65 \%)$ & $11(35 \%)$ & \multirow[t]{2}{*}{$0.015^{*}$} \\
\hline Female & $24(44 \%)$ & $22(92 \%)$ & $2(8 \%)$ & \\
\hline \multicolumn{5}{|l|}{ Education level } \\
\hline Primary & $4(7 \%)$ & $4(100 \%)$ & 0 & \multirow[t]{4}{*}{0.4688} \\
\hline Secondary & $15(27 \%)$ & $12(80 \%)$ & $3(20 \%)$ & \\
\hline Tertiary & $34(62 \%)$ & $25(73 \%)$ & $9(27 \%)$ & \\
\hline Unanswered & $2(4 \%)$ & & & \\
\hline \multicolumn{5}{|l|}{ Healthcare } \\
\hline Medical/GP card & $37(67 \%)$ & $32(86 \%)$ & $5(14 \%)$ & \multirow[t]{3}{*}{$0.0074 *$} \\
\hline Neither & $17(31 \%)$ & $9(53 \%)$ & $8(47 \%)$ & \\
\hline Unanswered & $1(2 \%)$ & & & \\
\hline \multicolumn{5}{|l|}{ Cost of vaccine } \\
\hline Access to free Vaccine. & $41(75 \%)$ & $33(80 \%)$ & $8(20 \%)$ & \multirow[t]{2}{*}{0.22} \\
\hline Pay for vaccine & $14(25 \%)$ & $9(64 \%)$ & $5(36 \%)$ & \\
\hline
\end{tabular}


In total, $76 \%$ participants received the influenza vaccine for the 2019 season, meeting WHO target coverage rate ([25]; Table 2). Levels of vaccination were similar throughout age distributions. There was a notable sex difference, 22 of 24 female patients $(92 \%)$ being vaccinated compared with 20 of 31 males $(65 \%)$ (chi-squared $<0.05$; Table 1). Vaccine uptake was marginally lower in the preceding years (Table 2). There was consistency with the same patients not engaging in vaccination; however, true rates could be clouded by recall bias.

Most patients (67\%; Table 3 ) had previously received information regarding the seasonal influenza vaccine. The majority $(78 \%)$ specified that information was given by healthcare staff. Within this group, various media channels were stated as a secondary information source. For the most part, patients found previous information helpful; $62 \%$ reported it as good or very good, while the remaining $30 \%$ reported it as moderately useful (Table 3). Ten of 13 unvaccinated patients elaborated on reasons for non-vaccination. The stated reasons included the incorrect belief that vaccination was redundant in those with hypogammaglobulinemia, that vitamin supplements gave sufficient protection, a lack of concern about contracting influenza, or being too unwell to receive it. Association between receiving information and vaccine uptake fell short of statistical significance (chi-squared $p=0.09$;

Table 2 Vaccination and health status. In the 2019/20 season, $76 \%$ of participants received the influenza vaccine. Numbers were lower in preceding years, as was recall. The majority of participants were not concerned about contracting influenza and reported positively on health status

\begin{tabular}{|c|c|c|c|}
\hline \multicolumn{4}{|c|}{ Influenza vaccination } \\
\hline Year & Yes $(\%)$ & No $(\%)$ & Unsure (\%) \\
\hline 2019 & $42(76 \%)$ & $13(24 \%)$ & 0 \\
\hline 2018 & $39(71 \%)$ & $15(27 \%)$ & $1(2 \%)$ \\
\hline 2017 & $37(67 \%)$ & $13(24 \%)$ & $5(9 \%)$ \\
\hline 2016 & $38(69 \%)$ & $11(20 \%)$ & $6(11 \%)$ \\
\hline 2015 & $31(56 \%)$ & $12(22 \%)$ & $12(22 \%)$ \\
\hline \multicolumn{4}{|c|}{ Perception of Health: 1 bad, 10 very good } \\
\hline Self-reported score & $N(\%)$ & & \\
\hline $10-7$ & $38(69 \%)$ & & \\
\hline $6-4$ & $12(22 \%)$ & & \\
\hline $3-1$ & $5(9 \%)$ & & \\
\hline \multicolumn{4}{|c|}{ Hospital admission in the last 12 months } \\
\hline Amount & Total & Infective cause & Non-infective cause \\
\hline 0 & $37(67 \%)$ & $\mathrm{n} / \mathrm{a}$ & $\mathrm{n} / \mathrm{a}$ \\
\hline 1 & $10(18 \%)$ & $6(60 \%)$ & $4(40 \%)$ \\
\hline$>1$ & $8(15 \%)$ & $6(75 \%)$ & $2(25 \%)$ \\
\hline \multicolumn{4}{|c|}{ Concern about developing influenza: 1 not worried, 10 very worried } \\
\hline Self-reported score & $N(\%)$ & & \\
\hline $10-7$ & $15(69 \%)$ & & \\
\hline $6-4$ & $19(9 \%)$ & & \\
\hline $3-1$ & $20(22 \%)$ & & \\
\hline Unanswered & $1(2 \%)$ & & \\
\hline \multicolumn{4}{|c|}{ Usefulness of influenza vaccine: 1 not useful; 10 very useful } \\
\hline Self-reported score & $N(\%)$ & & \\
\hline $10-7$ & $43(78 \%)$ & & \\
\hline $6-4$ & $11(20 \%)$ & & \\
\hline $3-1$ & 0 & & \\
\hline Unanswered & $1(2 \%)$ & & \\
\hline \multicolumn{4}{|c|}{ Danger of influenza vaccine: 1 not dangerous, 10 very dangerous } \\
\hline Self-reported score & $N(\%)$ & & \\
\hline $10-7$ & $6(11 \%)$ & & \\
\hline $6-4$ & $4(7 \%)$ & & \\
\hline $3-1$ & $45(82 \%)$ & & \\
\hline Unanswered & $1(2 \%)$ & & \\
\hline
\end{tabular}


Table 3 Vaccine-associated knowledge and education. The majority of participants correctly identified vaccine-preventable disease and populations at increased risk of severe disease from influenza. Most had received information about the influenza vaccine before, which they found useful, and healthcare professionals were stated as the primary source. Chi-squared results are represented by $p$ values

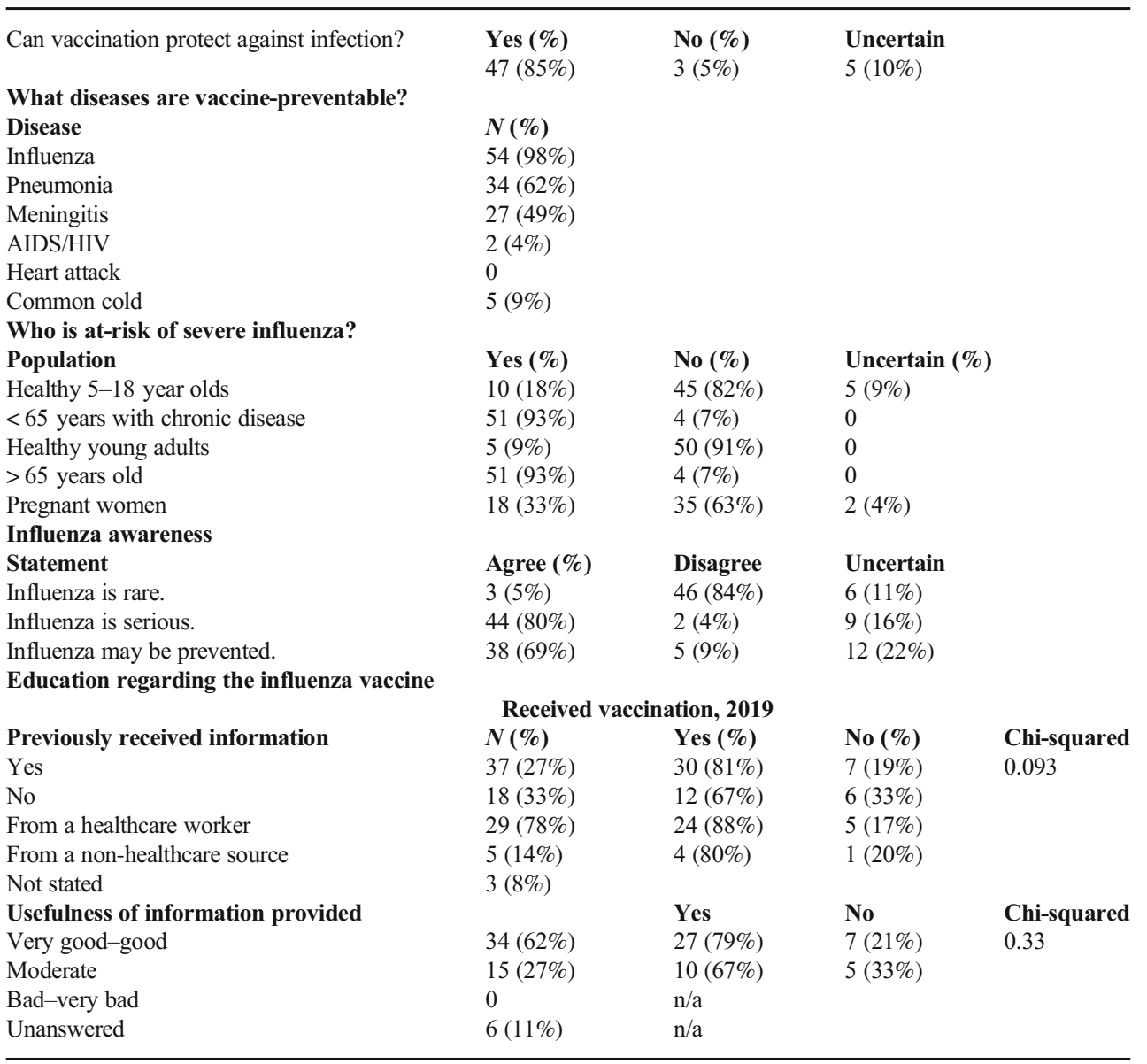

Table 3). However, interpretation and integration of healthcare advice is challenging to accurately quantify.

Most participants expressed only mild to moderate concern regarding contracting influenza, which was paralleled by good self-reported health status and relatively low hospital admission rate (Table 2). In general, participants regarded the influenza vaccine favorably; $78 \%$ felt it was useful, and $82 \%$ deemed it to be safe (Table 2). Patients understood that influenza was not rare $(84 \%)$, could be serious $(80 \%)$, and was vaccinepreventable (69\%; Table 3). Patients also correctly identified other vaccine-preventable diseases (Table 3). Furthermore, most participants (93\%) recognized that persons over 65 years of age and younger adults with chronic medical conditions were at risk of more severe illnesses from influenza and correctly recognized that healthy children $(45 ; 82 \%)$, and young adults without chronic conditions $(50 ; 91 \%)$ were not in the same risk category. Pregnant women are deemed an at-risk group; only $34 \%$ of our population identified this correctly [25].

Six (11\%) respondents live alone, 33\% have one co-habitant, $22 \%$ have 2 , and $34 \%$ have 3 or more co-habitants (Table 4 ). Despite excellent personal vaccine compliance and apparent influenza awareness, just over half (57\%) of those surveyed were aware that seasonal influenza vaccination is recommended for co-habitants. Most of this group (73\%) stated specific advice came from a healthcare source (Table 4). There was a positive correlation between receiving advice regarding vaccination of co-habitants and uptake in at least one household member (chisquared, $p<0.001)$. Unfortunately, overall household vaccination rates were suboptimal. Of the 49 participants (89\%) that live with at least one other person, less than half (48\%) reported vaccination of one or more household members. Twelve (24\%) had vaccine coverage of all household members (Table 4).

\section{Discussion}

The seasonal influenza vaccine is the most effective way of preventing influenza disease, and annual vaccination is recommended to close contacts of high-risk populations to limit transmission [3]. Despite potential disease severity, availability of an effective vaccine, and public campaigns to encourage uptake, compliance remains low in many susceptible groups [21, 22].

Patients with hypogammaglobulinemia are deemed at high risk of infective complication, in spite of adequate immunoglobulin replacement therapy $[17,27]$. Those with antibody deficiency might benefit modestly from vaccination and may rely greatly on herd immunity for optimal health outcomes [28]. The focus of this study was to assess seasonal influenza 
Table 4 Vaccination of co-habitants. Most participants had at least one household member. Over half were aware that vaccination is indicated for co-habitants, but less than one quarter had full vaccine cover at home.
Awareness about vaccination for co-habitants was correlated with increased uptake. Chi-squared results are represented by $p$ values, ${ }^{*} p<0.05$

$\begin{array}{ll}\text { Household contacts } & \\ \text { Live Alone } & 6(11 \%) \\ 1 & 18(33 \%) \\ 2 & 12(22 \%) \\ \geq 3 & 19(34 \%)\end{array}$

\begin{tabular}{|c|c|c|c|c|c|}
\hline \multicolumn{6}{|c|}{ Vaccination of co-habitants } \\
\hline & $N(\%)$ & All co-habitants & Some co-habitants & \multicolumn{2}{|l|}{ None } \\
\hline Have co-habitants & $49(89 \%)$ & $12(24 \%)$ & $\mathrm{n} / \mathrm{a}$ & \multicolumn{2}{|l|}{$25(51 \%)$} \\
\hline Lives with 1 & $18(37 \%)$ & $8(44 \%)$ & $\mathrm{n} / \mathrm{a}$ & \multicolumn{2}{|l|}{$10(59 \%)$} \\
\hline Lives with $\geq 2$ & $31(63 \%)$ & $4(13 \%)$ & $12(39 \%)$ & \multicolumn{2}{|l|}{$15(48 \%)$} \\
\hline \multicolumn{6}{|c|}{ Aware that cohabitants should be vaccinated } \\
\hline & & \multicolumn{4}{|c|}{$\geq 1$ Co-habitant vaccinated } \\
\hline & & $N(\%)$ & Yes $(\%)$ & No $(\%)$ & Chi-squared \\
\hline Aware of vaccination & & $28(57 \%)$ & 22 & 6 & $<0.001^{*}$ \\
\hline Not aware & & $21(43 \%)$ & 1 & 20 & \\
\hline \multicolumn{6}{|l|}{ Information source } \\
\hline \multicolumn{2}{|c|}{ Informed by healthcare worker } & \multicolumn{4}{|l|}{$19(68 \%)$} \\
\hline \multicolumn{2}{|c|}{ Informed by non-healthcare worker } & \multicolumn{4}{|l|}{$7(25 \%)$} \\
\hline \multicolumn{2}{|l|}{ Unanswered } & \multicolumn{4}{|l|}{$2(7 \%)$} \\
\hline
\end{tabular}

vaccine in patients and co-habitants of those receiving IgRT. We report a reassuring $76 \%$ uptake of the influenza vaccine during the 2019/20 season, which meets the WHO target coverage rate for at-risk groups [4] (Table 2). Compliance was $73 \%$ in those $<65$ years, exceeding uptake rates of agedmatched patients with other chronic diseases in numerous developed nations [21-24]. This was a single-center study with a small sample size; however, our results are in keeping with two North American surveys for the 2016/17 season. One reported $75 \%$ uptake among one thousand adults with a primary antibody deficiency; the other reported $76 \%$ in over 600 patients with CVID [25, 29]. Neither study investigated patient insight or vaccination of co-habitants.

In our study, vaccination rates were consistent between age groups, but there was a sex bias; $92 \%$ compliance among females, compared with $65 \%$ in males (chi-squared, $p<0.05$; Table 1). The reason for this is unclear. A gender difference in vaccine uptake is not universally reported. International data is mixed; many report no difference, several studies find men are more likely to receive vaccination than women, and others report the reverse [30-32].

Previous studies have shown certain factors are associated with increased vaccine uptake, knowledge that influenza is common and can be serious, trust in the safety of vaccination, and physician recommendation [21, 23, 24]. Many of these factors were identified in our study, and it is widely acknowledged that recommendation by a healthcare worker is one of the strongest modifiable factors to encourage vaccine uptake $[33,34]$. Our data support the important role of physicians in vaccine advocacy, particularly concerning advice for vaccination of co-habitants (Table 4). Various studies report the misconception that the influenza vaccine can cause an acute influenza infection is a common barrier to vaccination [23]. This was not prevalent in our group.

Self-identification, awareness, and knowledge among patients receiving IgRT highlight an understanding that is often absent in other at-risk cohorts. Many perceived barriers to vaccination were not present, for example, mistrust or poor understanding of its role in preventing disease [22, 23] (Table 3). Interestingly, population-based research indicates that the inability to self-identify as "at-risk" is a major barrier to vaccine uptake, particularly in those $<65$ years of age [21, 22, 35]. IgRT is a relatively intrusive therapy, and historically, patients have a high rate of healthcare attendances, thus allowing abundant opportunity for patient education. Furthermore, frequent interactions could foster self-identification as being susceptible to infection, making patients more cautious in seeking vaccination [36]. We did not record the duration of $\operatorname{IgRT}$ for each participant, so we are unable to specifically comment on frequency of healthcare interactions. Over two-thirds of our participants have access to free public healthcare through a medical/GP card. Correlation between medical/GP card ownership and vaccine uptake was significant (chi-squared $<0.05$; Table 2). Similarly, previous Irish data found that having free healthcare was a positive predictor for vaccination [21]. However, when our population was asked specifically about cost incurred by vaccination, there was no significant difference in vaccine uptake between those who paid compared with those 
who were vaccinated for free (chi-squared, $p=0.22$; Table 1 ). Medical card ownership and increased vaccine uptake are likely multifactorial and not solely based on availability of free vaccination. Cost as a barrier to vaccination is deemed by many physicians to be a foregone conclusion; however, it is an area that merits further scrutiny. Interestingly, a population-based survey in North America demonstrated a divergence in opinion between patients and healthcare providers in this regard. In a setting where access to publicly funded healthcare is limited, a minority of patients viewed cost as a barrier to vaccination, whereas up to two-thirds of physicians believed that monetary concerns were a primary deterrent $[35,37]$. As countries strive toward optimal vaccine coverage, efforts are continually being made to identify barriers for engagement. These results emphasize that education and awareness of the influenza vaccine may surpass access to free vaccination; as one is less likely to seek immunization, if unaware of its benefit, regardless of cost.

There was a low rate of vaccine uptake in co-habitants; only 12 participants (24\%) had full vaccine cover at home. This study shows a correlation between advice for vaccination of co-habitants and rate of coverage in household members (chi-squared, $p<0.001$; Table 4). Similar rates of vaccination coverage have been documented by others that assessed household members of those with chronic disease [38]. The age, risk profile, and health of co-habitants were not recorded in our data; thus, we are unable to discriminate between household members that were vaccinated to protect our patient, or for another reason. Nonetheless, these findings do highlight a significant gap in vaccine coverage that exposes our cohort to increased transmission risk. This could be modifiable with focused education regarding the importance of vaccination in all close contacts.

Vaccination of healthy household members may be perceived as challenging. However, data show that decreasing transmission to vulnerable individuals is a strong motivation for healthy adults [37]. In a university-based survey, $71 \%$ of unvaccinated healthy students indicated willingness to be vaccinated in light of helping others [37]. These findings emphasize that individuals can be incentivized to engage in vaccination uptake for altruistic means.

\section{Study Strengths and Limitations}

This is a small, single-institution study; thus, some findings may not be generalizable to other populations. A response rate of $57 \%$ exceeds many population-based questionnaires [24, 29], and $76 \%$ influenza vaccine uptake parallels findings from larger international surveys in a similar population $[29,34,35]$. High educational attainment was noted in participants, $62 \%$ holding a tertiary level qualification, which in theory could self-bias toward active engagement with healthcare information. Contrary to this, others have demonstrated that educational level is not a selfdetermining predictor of vaccine uptake $[39,40]$.

The questionnaire was extensive and previously validated. Self-selection of those in favor of vaccination could predispose to engagement in the questionnaire. There is no national registry for influenza vaccination to allow us to compare our vaccination rate with an objective measure. However, many studies on self-reported influenza vaccine status have established robust validity in a questionnaire-based approach $[25,40]$. Moreover, data collection took place immediately after the vaccination season, thus limiting recall bias.

\section{Conclusion}

This study shows satisfactory influenza vaccine uptake among patients receiving IgRT in a large referral hospital. Our population meets WHO target vaccine coverage, parallels international findings, and greatly exceeds influenza immunization in other high-risk groups $[21,25,29]$. The majority of patients had previously received advice on seasonal vaccination, felt well-informed, and stated a physician as their primary information source.

Vaccine uptake among household members was low, thus potentially increasing influenza transmission risk. To our knowledge, this is the first time that this has been reported in an immunodeficiency cohort. This study demonstrates a need to specifically recommend immunization to close contacts and household members of these patients. Enhancing vaccination rates in cohabitants to those at-risk is likely achievable. In light of the current study, we recommend healthcare workers emphasize the importance of an annual influenza vaccine to patients on IgRT and educate them that vaccination of close contacts offers additional protection. For optimal impact, this advice should be teamed with complementary written information. A follow-up study is being planned to assess the outcome of this intervention and further delineate vaccination uptake rate of co-habitants.

Acknowledgments We thank our participants for completing the questionnaire and all the staff in St James's Hospital Immunology day ward for facilitating the study.

Author Contributions FC and $\mathrm{NC}$ conceived the research and designed the study. FC interpreted data and wrote the manuscript; FC, CK, AS, DE, and $\mathrm{NC}$ contributed to the acquisition of clinical data and recruitment of participants. All authors read and approved the manuscript.

\section{Compliance with Ethical Standards}

Conflict of Interest The authors declare that they have no conflicts of interest. 


\section{Appendix}

Section A\&B. These sections are designed to gather information about your sociodemographic characteristics and health status.

A1. Sex: $\square$ Male $\square$ Female

A2. How old were you on your last birthday?

A3. What is your highest level of education? $\square$ Primary School $\square$ Secondary School $\square$ Third Level A4. What is your marital status? $\square$ Married $\square$ Single (never married) $\square$ Other A5. What is your occupation?

A6. How many people live with you?

B1. Do you have a $\square$ Medical Card $\square$ GP Visit Card $\square$ Neither

B2. Have you been hospitalised in the last year? $\square$ Yes $\square$ No, (how many times? Why?

1)

3)

B3. On a scale from 1 to 10, how would you classify your current state of health? (1 bad; 10 very good)

Section C. This section is designed to gather information about your knowledge of vaccinepreventable diseases.

C1. Vaccinations are interventions that protect against infectious disease? $\square$ Yes $\square$ No

C2. Which of the following diseases can be avoided with vaccination?

$\square$ flu $\quad \square$ pneumonia $\quad \square$ meningitis $\quad \square$ shingles $\quad \square$ AIDS / HIV

$\square$ hepatitis C $\quad \square$ heart attack $\quad \square$ cold

C3. In your opinion, which of the following subjects are at higher risk of developing severe forms of flu?

$\square$ children $<6$ months old $\square$ children and young persons (5-18 years) $\square<64$ years old with chronic conditions $\square$ healthy young adults $\square$ elderly ( $\geq 65$ years old) $\square$ pregnant women $\square$ other (please specify) 


\begin{tabular}{|l|l|l|l|}
\hline $\begin{array}{l}\text { C4. For each of the following statements indicate whether you are } \\
\text { in agreement, uncertain or disagree }\end{array}$ & agreement & uncertain & disagree \\
\hline Flu is rare & $\square$ & $\square$ & $\square$ \\
\hline Flu is serious & $\square$ & $\square$ & $\square$ \\
\hline Flu may be prevented & $\square$ & $\square$ & $\square$ \\
\hline
\end{tabular}

Section $\mathrm{D}$. This section is designed to gather information about your attitudes towards flu and the flu vaccine.

D1. On a scale from 1 to 10, how much are you worried about developing flu? (1 not worried; 10 very worried)

D2. On a scale from 1 to 10 , how useful do you believe vaccination to prevent flu? (1 not useful; 10 very useful)

D3. On a scale from 1 to 10 , how dangerous do you believe the flu vaccination to be? (1 not dangerous; 10 very dangerous)

D4. If you think it to be dangerous

why?

Section E. In this section I will ask you some questions on health-related behaviors.

E1. Did you receive a vaccination against flu in 2018? $\square$ Yes $\square$ No

Who advised you to have it?:

If no, why?

E2. Did you receive a vaccination against flu in previous years?

\begin{tabular}{|l|l|l|l|l|}
\hline & YES & NO & NOT SURE & REASON \\
\hline 2017 & $\square$ & $\square$ & $\square$ & \\
\hline 2016 & $\square$ & $\square$ & $\square$ & \\
\hline 2015 & $\square$ & $\square$ & $\square$ & \\
\hline 2014 & $\square$ & $\square$ & $\square$ & \\
\hline
\end{tabular}


E3. Do you intend to receive a vaccination against flu this winter?

$\square$ if yes,

why?

$\square$ if no,

why?

$\square$ if not sure,

why?

E4. Were any of your household members (wife/husband, children, caregiver, etc.) advised to get the flu vaccination?

$\square$ Yes $\square$ No $\square$ Not sure

If yes, by whom?

E5. Did they receive flu vaccine in 2018? $\square$ Yes $\quad \square$ No $\quad \square$ Not sure If yes, how many? of

E6. In your opinion, how much will it cost you to get the flu vaccination?

$\square$ it is totally at my charge $\quad \square$ it is totally free $\quad \square$ it is partially at my charge

$\square$ other

Section F. This section is designed to assess the sources from which you acquire information about flu vaccination

F1. Have you received information about flu vaccination before today?

$\square$ Yes $\square$ No, from whom?

F2. How useful did you believe previous information about flu vaccination to be?

$\square$ very bad $\square$ bad $\square$ moderate $\square$ good $\square$ very good 
F3. Do you feel you need more information about flu vaccination? $\square$ Yes $\square$ No

If yes,

why?

If no,

why?

Thank you for completing our questionnaire.

Please use the enclosed stamped addressed envelope to return the completed survey and signed consent form.

Address: Immunology Department, St James's Hospital, Dublin 8.

If you have any question please contact the Immunology Department on (01) 4164147.

Open Access This article is licensed under a Creative Commons Attribution 4.0 International License, which permits use, sharing, adaptation, distribution and reproduction in any medium or format, as long as you give appropriate credit to the original author(s) and the source, provide a link to the Creative Commons licence, and indicate if changes were made. The images or other third party material in this article are included in the article's Creative Commons licence, unless indicated otherwise in a credit line to the material. If material is not included in the article's Creative Commons licence and your intended use is not permitted by statutory regulation or exceeds the permitted use, you will need to obtain permission directly from the copyright holder. To view a copy of this licence, visit http://creativecommons.org/licenses/by/4.0/.

\section{References}

1. Vestergaard LS, Nielsen J, Krause TG, Espenhain L, Tersago K, Bustos Sierra N, et al. Excess all-cause and influenza-attributable mortality in Europe, December 2016 to February 2017. Euro Surveill. 2017;22(14):pii=30506. https://doi.org/10.2807/15607917.ES.2017.22.14.30506.

2. Molbak K, Espenhain L, Nielsen J, Tersago K, Bossuyt N, Denissov G, et al. Excess mortality among the elderly in European countries, December 2014 to February 2015. Euro Surveill. 2015 Mar 19;20(11):21065. https://doi.org/10.2807/ 1560-7917.es2015.20.11.21065.

3. Uyeki TM. Preventing and controlling influenza with available interventions. N Engl J Med. 2014;370(9):789-91.

4. WHO. Influenza (Seasonal) [Internet]. Available from: https:// www.who.int/news-room/fact-sheets/detail/influenza-(seasonal). Accessed 12 Dec 2019.

5. Vanhems P, Voirin N, Roche S, Escuret V, Regis C, Gorain C, et al. Risk of influenza-like illness in an acute health care setting during community influenza epidemics in 2004-2005, 2005-2006, and
2006-2007: a prospective study. Arch Intern Med. 2011;171(2): $151-7$.

6. Vaccines against influenza WHO position paper-November 2012. Wkly Epidemiol Rec. 2012;87(47):461-76. English, French. PMID: 23210147

7. Estabragh ZR, Mamas MA. The cardiovascular manifestations of influenza: a systematic review. Int J Cardiol. 2013;167(6):2397_ 403.

8. Joseph C, Togawa Y, Shindo N. Bacterial and viral infections associated with influenza. Influenza Other Respir Viruses. 2013;7(Suppl 2):105-13.

9. World Health Organization. Influenza (Seasonal). Fact sheet no. 211. Geneva, 2014 [Internet]. [updated 2017; cited Available from: https://www.who.int/mediacentre/factsheets/fs211/en/. Accessed 4 Jan 2020.

10. European Centre for Disease Prevention and Control. Key messages [Internet]. [updated 2019; cited Available from: https://ecdc. europa.eu/en/seasonal-influenza/facts/key-messages. Accessed 4 Jan 2020.

11. Mereckiene J, Cotter S, Nicoll A, Lopalco P, Noori T, Weber J, et al. Seasonal influenza immunisation in Europe. Overview of recommendations and vaccination coverage for three seasons: prepandemic (2008/09), pandemic (2009/10) and post-pandemic (2010/11). Euro Surveill. 2014;19(16):20780.

12. National Immunisation Advisory Committee [Internet]. [updated 2015; cited Available from: https://www.hse.ie/eng/health/ immunisation/hcpinfo/guidelines/immunisationguidelines.htm. Accessed 8 Nov 2019.

13. Gernez Y, Baker MG, Maglione PJ. Humoral immunodeficiencies: conferred risk of infections and benefits of immunoglobulin replacement therapy. Transfusion. 2018;58(Suppl 3):3056-64.

14. Chua I, Lagos M, Charalambous BM, Workman S, Chee R, Grimbacher B, et al. Pathogen-specific IgG antibody levels in immunodeficient patients receiving immunoglobulin replacement do 
not provide additional benefit to therapeutic management over total serum IgG. J Allergy Clin Immunol. 2011;127(6):1410-1.

15. Bonilla FA, Khan DA, Ballas ZK, Chinen J, Frank MM, Hsu JT, et al. Practice parameter for the diagnosis and management of primary immunodeficiency. J Allergy Clin Immunol. 2015;136(5): 1186-205.e1.

16. van Assen S, Holvast A, Telgt DSC, Benne CA, de Haan A, Westra $\mathrm{J}$, et al. Patients with humoral primary immunodeficiency do not develop protective anti-influenza antibody titers after vaccination with trivalent subunit influenza vaccine. Clin Immunol. 2010;136(2):228-35.

17. Mieves JF, Wittke K, Freitag H, Volk HD, Scheibenbogen C, Hanitsch LG, et al. Influenza vaccination in patients with common variable immunodeficiency (CVID). Curr Allergy Asthma Rep. 2017;17(11):78.

18. van Assen S, de Haan A, Holvast A, Horst G, Gorter L, Westra J, et al. Cell-mediated immune responses to inactivated trivalent influenza-vaccination are decreased in patients with common variable immunodeficiency. Clin Immunol. 2011;141(2):161-8.

19. Liu Y, Wu Y, Lam KT, Lee PPW, Tu W, Lau YL, et al. Dendritic and $\mathrm{T}$ cell response to influenza is normal in the patients with $\mathrm{X}$ linked agammaglobulinemia. J Clin Immunol. 2012;32(3):421-9.

20. Ghendon YZ, Kaira AN, Elshina GA. The effect of mass influenza immunization in children on the morbidity of the unvaccinated elderly. Epidemiol Infect. 2006;134(1):71-8.

21. Giese C, Mereckiene J, Danis K, O'Donnell J, O'Flanagan D, Cotter $\mathrm{S}$, et al. Low vaccination coverage for seasonal influenza and pneumococcal disease among adults at-risk and health care workers in Ireland, 2013: the key role of GPs in recommending vaccination. Vaccine. 2016;34(32):3657-62.

22. Bertoldo G, Pesce A, Pepe A, Pelullo CP, Di Giuseppe G, Collaborative Working Group, et al. Seasonal influenza: knowledge, attitude and vaccine uptake among adults with chronic conditions in Italy. PLoS One. 2019;14(5):e0215978.

23. Bödeker B, Remschmidt C, Schmich P, Wichmann O. Why are older adults and individuals with underlying chronic diseases in Germany not vaccinated against flu? A population-based study. BMC Public Health. 2015;15:618.

24. Dubé E, Gagnon D, Kiely M, Defay F, Guay M, Boulianne N, et al. Seasonal influenza vaccination uptake in Quebec, Canada, 2 years after the influenza $\mathrm{A}(\mathrm{H} 1 \mathrm{~N} 1)$ pandemic. Am J Infect Control. 2014:42(5):e55-9.

25. Jorgensen P, Mereckiene J, Cotter S, Johansen K, Tsolova S, Brown $\mathrm{C}$, et al. How close are countries of the WHO European Region to achieving the goal of vaccinating $75 \%$ of key risk groups against influenza? Results from national surveys on seasonal influenza vaccination programmes, 2008/2009 to 2014/2015. Vaccine. 2018;36(4):442-52.

26. Nolan A. An extension in eligibility for free primary care and avoidable hospitalisations: a natural experiment. Soc Sci Med. 2011;73(7):978-85.

27. Shrestha P, Karmacharya P, Wang Z, Donato A, Joshi AY. Impact of IVIG vs. SCIG on IgG trough level and infection incidence in primary immunodeficiency diseases: a systematic review and meta- analysis of clinical studies. World Allergy Organ J. 2019;12(10): 100068.

28. Medical Advisory Committee of the Immune Deficiency Foundation, Shearer WT, Fleisher TA, Buckley RH, Ballas Z, Ballow M, et al. Recommendations for live viral and bacterial vaccines in immunodeficient patients and their close contacts. $\mathrm{J}$ Allergy Clin Immunol. 2014;133(4):961-6.

29. Ballow M, Henderson T, Scalchunes C, Blaese RM. Seasonal viral influenza among persons with primary antibody immunodeficiency. J Allergy Clin Immunol Pract. 2019;7(3):1058-1060.e3.

30. Dyda A, MacIntyre CR, McIntyre P, Newall AT, Banks E, Kaldor $\mathrm{J}$, et al. Factors associated with influenza vaccination in middle and older aged Australian adults according to eligibility for the national vaccination program. IAVI Rep. 2015;33:3299-305.

31. Social determinants of health and seasonal influenza vaccination in adults $\geq 65$ years: a systematic review of qualitative and quantitative data. BMC Public Health. 2013;13:388. https://doi.org/10.1186/ 1471-2458-13-388.

32. Endrich MM, Blank PR, Szucs TD. Influenza vaccination uptake and socioeconomic determinants in 11 European countries. Vaccine. 2009;27:4018-24.

33. Tsui HY, Lau JTF, Lin C, Choi KC. Prevalence of seasonal influenza vaccination and associated factors in people with chronic diseases in Hong Kong. Epidemiol Infect. 2013;141(2):377-89.

34. Vinograd I, Baslo R, Eliakim-Raz N, Farbman L, Taha A, Sakhnini $\mathrm{A}$, et al. Factors associated with influenza vaccination among adult cancer patients: a case-control study. Clin Microbiol Infect. 2014;20(9):899-905.

35. Johnson DR, Nichol KL, Lipczynski K. Barriers to adult immunization. Am J Med. 2008;121(7 Suppl 2):S28-35.

36. Oris L, Luyckx K, Rassart J, Goubert L, Goossens E, Apers S, Arat $\mathrm{S}$, Vandenberghe J, Westhovens R, Moons P. Illness identity in adults with a chronic illness. J Clin Psychol Med Settings. 2018;25(4):429-40. https://doi.org/10.1007/s10880-018-9552-0.

37. Bednarczyk RA, Chu SL, Sickler H, Shaw J, Nadeau JA, McNutt LA, et al. Low uptake of influenza vaccine among university students: evaluating predictors beyond cost and safety concerns. Vaccine. 2015;33(14):1659-63.

38. Yue X, Black CL, Williams WW, Lu PJ, Srivastav A, Amaya A, et al. Influenza vaccination among adults living with persons at high-risk for complications from influenza during early 2016-17 influenza season. Vaccine. 2018;36(52):7987-92.

39. Mangtani P, Shah A, Roberts JA. Validation of influenza and pneumococcal vaccine status in adults based on self-report. Epidemiol Infect. 2007;135(1):139-43.

40. Kroneman MW, van Essen GA, Tacken MAJB, Paget WJ, Verheij $R$. Does a population survey provide reliable influenza vaccine uptake rates among high-risk groups? A case-study of the Netherlands. Vaccine. 2004;22(17-18):2163-70.

Publisher's Note Springer Nature remains neutral with regard to jurisdictional claims in published maps and institutional affiliations. 